\title{
CONCEPÇÕES DE LINGUAGEM E DE LEITURA NO ENEM DE LÍNGUA INGLESA ${ }^{1}$
}

\author{
Amanda Petry Radünz* \\ Patrícia Marcurzo
}

\begin{abstract}
RESUMO: No Brasil, o Exame Nacional do Ensino Médio (Enem) exerce influências nos contextos de ensino por ser utilizado como critério de acesso a importantes universidades públicas e privadas e como critério de participação em projetos sociais que viabilizam esse acesso. As influências que o Enem exerce nos contextos de ensino inclui as concepções teóricas que o subjazem, visto que as questões que compõem o exame são fundamentadas em teorias que, consequentemente, estão presentes na escola. O objetivo deste trabalho é analisar as concepções de linguagem e de leitura que subjazem as questões do Enem de Língua Inglesa (Enem-LI). Para tanto, foram consideradas, principalmente, as concepções de linguagem como meio de interação e como instrumento de comunicação; e as concepções de leitura como produção de sentido e como decodificação. Foi analisado um total de 40 questões de LI de oito edições do exame, com ênfase na análise semântica dos enunciados das questões. Os resultados apontam que ambas as concepções de linguagem e de leitura subjazem diferentes questões do exame, o que pode indicar um direcionamento para visões mais atuais de linguagem como gênero e de leitura como letramento, privilegiadas em documentos oficiais que orientam o ensino de línguas no país.
\end{abstract}

PALAVRAS-CHAVE: Concepções de leitura; Concepções de linguagem; Enem; Língua Inglesa.

\section{Introdução}

No Brasil, o Exame Nacional do Ensino Médio (Enem) avalia o desempenho geral dos estudantes durante o Ensino Médio. Além disso, desde a sua implementação, o desempenho dos estudantes que prestam o Enem pode ser utilizado para o acesso a universidades e à participação em programas sociais que viabilizam esse acesso, como o Programa Universidade para Todos (Prouni) e o Programa de Financiamento Estudantil (FIES). Dessa

\footnotetext{
${ }^{1}$ Trabalho desenvolvido para a disciplina de "Concepções de linguagem, ensino e aprendizagem", ministrada pela Prof $^{a} \mathrm{Dr}^{\mathrm{a}}$ Luciane Kirchhof Ticks, ofertada pela linha de pesquisa Linguagem no Contexto Social, do Programa de Pós-graduação em Letras da Universidade Federal de Santa Maria, no $1^{\circ}$ semestre de 2020.

* Doutoranda e mestre em Letras pela Universidade Federal de Santa Maria (UFSM). Bolsista de doutorado da Coordenação de Aperfeiçoamento de Pessoal de Nível Superior, CAPES, Brasil.

** Doutora em Letras pela Universidade Federal de Santa Maria (UFSM). Professora do Departamento de Letras Estrangeiras Modernas e do Programa de Pós-Graduação em Letras da UFSM.
} 
forma, por ser utilizado como ferramenta de ingresso em importantes universidades federais brasileiras, como, por exemplo, a Universidade Federal de Minas Gerais (UFMG), a Universidade Federal do Rio Grande do Sul (UFRGS) e a Universidade Federal do Rio de Janeiro (UFRJ), entre outras, o Enem pode apresentar influências no contexto de ensino e de aprendizagem nas escolas públicas. Para mais, o Enem "passa a fazer parte da vida de estudantes e professores do EM, principalmente" (BLANCO, 2013, p. 13).

A influência que o Enem exerce no contexto do EM inclui as concepções e fundamentações teóricas que o subjazem, visto que os testes de cada área do conhecimento que compõem o exame (Ciências Humanas, Ciências da Natureza, Linguagens e Matemática) são fundamentados em teorias que, consequentemente, estão presentes na escola. O enfoque deste trabalho recai sobre o Enem de Língua Inglesa (Enem-LI), que faz parte do teste da área de Linguagens. O Enem-LI é elaborado "com base na Matriz de Referência para o Enem 2009 e no capítulo específico sobre Língua Estrangeira (LE) das Orientações Curriculares Nacionais para o Ensino Médio (OCEM) (Brasil, 2006)" (RAUBER, 2012, p. 14), que apresentam a concepção de leitura como produção de sentido, como letramento, vinculada à concepção de linguagem como meio de interação, como gênero. Nesse contexto, pelo menos dois estudos prévios já investigaram esse teste a fim de, dentre outros objetivos, verificar em que medida essas concepções efetivamente subjazem às questões.

Um dos estudos foi realizado em nível de mestrado (RAUBER, 2012) e analisou duas edições do exame, e o outro, em nível de doutorado (AVELAR, 2015), analisou três edições. Ambos os estudos identificaram que a concepção de leitura que subjaz o EnemLI é a leitura como decodificação (RAUBER, 2012, p. 82; AVELAR, 2012, p. 58). Dessa forma, no Enem-LI, de acordo com Rauber (2012, p. 82), a leitura "é entendida predominantemente como um ato passivo do examinando diante do texto, em uma prática na qual é enfatizada a tradução de itens lexicais e de trechos de textos", e, de acordo com Avelar (2015, p. 58), o examinando precisa "levantar hipóteses sobre o assunto tratado no texto e verificá-las durante a leitura”, em um processo que "dá a impressão de que [...] [o] leitor ocupa papel central durante a leitura", o que não acontece efetivamente. 
A fim de se somar às discussões realizadas nesses estudos prévios, o presente trabalho busca analisar as concepções de linguagem e de leitura que subjazem o Enem-LI, apresentando a análise de um corpus maior que o corpus dos estudos prévios: um total de oito edições do Enem, aplicadas entre os anos de 2010 e 2017. Assim, acredita-se que seja possível discutir de forma mais aprofundada as concepções de linguagem e de leitura que subjazem esse teste. Para tanto, primeiramente são revisadas duas concepções de linguagem e de leitura, e, em seguida, é apresentada a análise acerca das concepções que subjazem o teste em questão.

\section{Concepções de linguagem no ensino de línguas}

O ensino de línguas no Brasil foi historicamente subsidiado por pelo menos três importantes concepções de linguagem: a concepção de linguagem como expressão do pensamento, subsidiada pela perspectiva behaviorista de aprendizagem; a concepção de linguagem como instrumento de comunicação, subsidiada pela perspectiva cognitivista de aprendizagem; e a concepção de linguagem como meio de interação, subsidiada pela perspectiva sócio-cultural de aprendizagem. Essa última concepção de linguagem demonstra-se a mais desejável pelos documentos oficiais que orientam o atual contexto de ensino no país, como, por exemplo, as OCEM (Brasil, 2006). Porém, sabe-se que, na prática do ensino de línguas, as outras duas concepções de linguagem também se fazem presentes, principalmente a de linguagem como instrumento de comunicação. Dessa forma, a presente seção apresenta, primeiramente, a concepção entendida como a mais recente, que é a linguagem como meio de interação, e, então, a concepção de linguagem como instrumento de comunicação, bem como as concepções de aprendizagem que subsidiam cada uma delas.

A concepção de linguagem como meio de interação foi influenciada pela perspectiva sociocultural de aprendizagem, desenvolvida principalmente por Lev Vygotsky (18961934). Para essa perspectiva, é essencial o entendimento de que, para o processo de aprendizagem ocorrer, ele precisa ser pensado dentro dos contextos sociais, históricos e culturais. Nesse sentido, Vygotsky (2001, p. 149) aponta que 
o desenvolvimento do pensamento e da linguagem depende dos instrumentos de pensamento e da experiência sociocultural da criança. (...) O desenvolvimento do pensamento da criança depende de seu domínio dos meios sociais do pensamento, isto é, da linguagem. (...) O pensamento verbal não é uma forma natural e inata de comportamento, mas uma forma histórico-social.

Dessa forma, para Vygotsky, o aprendizado ocorre por meio das palavras; ou seja, as palavras guiam o processo de formação de conceitos (FRIEDRICH, 2012, p. 83, 85). Os estudos de Vygotsky também desencadearam no entendimento da Zona de Desenvolvimento Proximal (ZDP): “a relação entre os processos 'maduros' e 'em maturação' [...]; a relação entre o que a criança pode fazer independentemente e em colaboração com outros" (NEWMAN; HOLZMAN, 1993, p. 72), o que indica que qualquer processo de aprendizagem e de desenvolvimento depende da socialização do aprendiz, do contato com os outros e com o mundo exterior. É por meio da linguagem que esses processos de aprendizagem e de desenvolvimento ocorrem, visto que é por meio da linguagem que a criança estabelece contato com o mundo exterior.

Assim, a partir dessa perspectiva, a linguagem é entendida como meio de interação humana, utilizada para agir dentro de contextos sócio-históricos e ideológicos e constituir discursos. Além disso, "é encarada como um conjunto de práticas sociais e de linguagem historicamente situadas, em diversas esferas de comunicação da atividade humana" (GOMES, 2013, p. 44). Para Bakhtin (1999, p. 114-115), nessa mesma perspectiva, a linguagem sempre é o produto da interação entre dois indivíduos: a palavra sempre se dirige a um interlocutor, e varia de acordo com esse interlocutor e com o contexto e a situação em que ocorre. Portanto, a comunicação verbal jamais pode ser compreendida fora da situação concreta, fora do contexto, visto que sempre é acompanhada de atos de caráter não-verbal (gestos, atos simbólicos; etc.), e, às vezes, é só auxiliar desses atos (BAKHTIN, 1999, p. 126). Para Bakhtin (1999, p. 128), ainda, a linguagem sempre ocorre em uma situação que possui um auditório organizado e certas fórmulas para se concretizar; e reflete "ideologicamente o tipo, a estrutura, os objetivos e a composição social do grupo".

A concepção de linguagem como meio de interação deu espaço para a idealização, inicialmente por Paulo Freire, de perspectivas críticas de linguagem, que consistem, 
conforme aponta Motta-Roth (2008, p. 362), citando Freire, na "percepção das relações entre texto e contexto". A perspectiva crítica entende linguagem como gênero: uma atividade pertinente, mediada pela linguagem num dado contexto de situação (MOTTAROTH, 2006, p. 145). Assim, pedagogias de ensino de língua como gênero englobam "além do léxico e da gramática", o ensino do "contexto social, do discurso e da ideologia" (MOTTA-ROTH, 2008, p. 351).

Previamente ao desenvolvimento dessa concepção de linguagem como meio de interação, que implica o entendimento e o ensino da linguagem de forma contextualizada, a concepção de linguagem como instrumento de comunicação, atrelada à perspectiva cognitivista de aprendizagem, desenvolvida, principalmente, por Noam Chomsky e Jean Piaget, mais ativamente entre as décadas de 60 e 70, se preocupava principalmente com o papel da mente no processo da linguagem.

Chomsky (2009, p. 312, 314) se insere na perspectiva biolinguística, que vê a língua "em todos seus aspectos - som, significado, estrutura - como um estado de algum componente da mente", que "participa do uso e da aquisição da linguagem". A linguagem, portanto, é entendida como a ferramenta que utilizamos não só como meio de comunicação, mas também como meio de simbolização (CHOMSKY, 2009, p. 318). Para Chomsky (2009, p. 320-321), o processo de simbolizar é possível por meio da Gramática Universal $(\mathrm{GU})$, que oferece a todos seres humanos

primeiro, um inventário estruturado dos itens lexicais possíveis que estão relacionados com ou talvez sejam idênticos aos conceitos, que são os elementos dos "poderes cognitivos"; segundo, meios para se construir a partir desses itens lexicais a infinita variedade de estruturas internas que entram no pensamento, na interpretação, no planejamento e em outros atos mentais humanos, e às vezes são exteriorizados (...)

Dessa forma, Chomsky (2009, p. 323) apresenta "três fatores que participam do desenvolvimento da linguagem no indivíduo": 1) os "fatores genéticos" - representados pela GU, comum a todos os seres humanos; 2) a "experiência - que leva à variação"; e 3) os "princípios não específicos da faculdade da linguagem". Além disso, a teoria dos 
Princípios e Parâmetros (P\&P), desenvolvida por Chomsky como uma adequação dos conceitos da GU, indica que os Princípios “regem ‘todas' línguas naturais”, e compreendem “as propriedades das línguas humanas geneticamente determinadas" e que não dependem da aprendizagem (KATO, 2005, p. 186). Por outro lado, os Parâmetros dão conta das variações existentes entre as línguas, e, portanto, precisam ser aprendidos (KATO, 2005, p. 191).

Assim como Chomsky, Piaget foi um pesquisador que priorizou o estudo do desenvolvimento cognitivo, ao endereçar a distância entre as capacidades cognitivas das crianças e as práticas de ensino utilizadas pelos professores (MUNARI, 2010, p. 15). Destacase, na pesquisa de Piaget, o método de aprendizagem por meio do exemplo, em que o aluno deve "experimentar ativamente, para reconstruir por si mesmo, aquilo que tem que aprender" (MUNARI, 2010, p. 17-18).

Sob influência dessa perspectiva de aprendizagem, a linguagem é entendida "como um código, isto é, um conjunto de signos que se combinam segundo regras", e, no processo de aprendizagem da língua, o aluno deve ser exposto ao sistema alfabético e à gramática, para que possa "utilizar o código, ora como emissor - codificador - ora como recebedor - decodificador, o que caracterizou o ensino da língua como sendo descritivo" (GOMES, 2013, p. 44).

No contexto de ensino de Língua Estrangeira (LE), mais especificamente, o ensino de inglês como LE, no Brasil, a habilidade de leitura é tradicionalmente privilegiada, devido ao entendimento de que essa habilidade é a mais socialmente relevante para os estudantes brasileiros, que utilizam o inglês no dia-a-dia principalmente para a "leitura de literatura técnica ou de lazer" (BRASIL, 1998, p. 20). Essa habilidade também é a única avaliada pelo Enem-LI. Dessa forma, a próxima seção apresenta as concepções de leitura que subjazem as práticas de ensino de línguas no Brasil.

\section{Concepções de leitura no ensino de línguas}

As concepções de linguagem apresentadas na seção anterior se relacionam com pelo menos duas concepções de leitura: a concepção de linguagem como meio de interação se 
relaciona com a concepção de leitura como produção de sentido, enquanto "as concepções de linguagem como expressão do pensamento e como instrumento de comunicação relacionam-se diretamente com a concepção de leitura voltada ao texto, tomando-a como decodificação" (FUZA; MENEGASSI, 2009, p. 16-17). Essas duas concepções são apresentadas, nesta seção, relacionadas também aos modelos de leitura, que podem ser entendidos como diferentes maneiras de processar os textos, que são usadas de acordo com nossos objetivos de leitura (NUTTALL, 1996, p. 16).

O primeiro modelo de leitura é o modelo ascendente de leitura, em que ocorre um processo linear e passivo por parte do leitor: o significado está exclusivamente presente no texto e é extraído por meio do reconhecimento de palavras e orações (NUTTALL, 1996, p. 17). O segundo é o modelo descendente de leitura, em que o leitor utiliza seu conhecimento prévio para interpretar hipóteses, formular inferências e entender o texto (NUTTALL, 1996, p. 16). Ao contrário do modelo ascendente, no modelo descendente, os significados trazidos pelo leitor, e não só os que estão no texto, também são ativados para uma compreensão global do texto. Por fim, o terceiro é o modelo interativo de leitura, em que os modelos ascendente e descendente de leitura são aplicados conscientemente para prever os possíveis significados do texto e confirmar se esses significados realmente foram estabelecidos pelo autor (NUTTALL, 1996, p. 17).

A concepção de leitura como produção de sentido, ou como letramento, assim como a concepção de linguagem meio de interação, demonstra-se a mais desejável para o atual contexto de ensino de línguas, por entender a leitura como um ato de posicionar-se em relação a um discurso, com a compreensão de que todo discurso é resultado e é composto de discursos anteriores, e que também gera novos discursos (ROJO, 2004, p. 3-4). Associa-se a essa concepção de leitura o modelo interativo de leitura.

No Brasil, tal concepção está presente nos documentos oficiais que orientam o ensino escolar. As OCEM (Brasil, 2006, p. 113), por exemplo, na seção sobre "Conhecimentos de LE", abordam a leitura como um processo que contribui "para ampliar a visão de mundo dos alunos, para trabalhar o senso de cidadania, para desenvolver a capacidade crítica, e para construir conhecimento em uma concepção epistemológica contemporânea". 
Dessa forma, o documento estabelece o entendimento de leitura como produção de sentido, em vez de um processo de extração de sentido,

pois não entende que os sentidos já estejam dados no texto, à espera da compreensão. Acredita, ainda, que os sentidos são construídos dentro de um contexto social, histórico, imerso em relações de poder. Daí ser a leitura uma atividade de linguagem que envolve conhecer o mundo, ter uma visão desse e refletir sobre as possibilidades e as conveniências de transformação social (BRASIL, 2006, p. 115-116).

Nesse contexto, a leitura como letramento (ou como produção de sentido) também envolve abordagens de ensino de gênero a partir de pedagogias explícitas de como a linguagem funciona para produzir significado, além de demonstrar preocupação com a realidade social dos textos em uso a fim de que os indivíduos possam adquirir o potencial linguístico para se juntar a novos domínios de atividade e poder social (COPE; KALANTZIS, 1993, p. 1 e 7). Ademais, Cope e Kalantzis (1993, p. 16 e 18, tradução nossa) indicam que, para que possam tornar-se "bons leitores" e "bons escritores", essas abordagens encorajam os alunos a serem críticos, e os oferecem novas maneiras de significar em contextos nãofamiliares.

As concepções de letramento envolvem também a noção de letramento crítico e de multiletramentos. Cervetti et al. (2001) apresentam três abordagens teóricas relacionadas ao letramento crítico: 1) a teoria social crítica, que indica que os significados nunca são dados nos textos, mas construídos, e esses significados envolvem a aquisição de conhecimento, poder, status e recursos materiais; 2) a abordagem Freiriana, que acredita que os temas justiça e força por emancipação sempre devem ter a atenção principal; e 3) a abordagem pós-estruturalista, que demonstra que os significados dos textos são construídos em conjunto com outros significados e práticas de contextos específicos.

A noção de multiletramentos, por sua vez, completa a noção tradicional da pedagogia de letramento na medida em que endereça simultaneamente dois aspectos de multiplicidade textual: 1) a multiplicidade de mídias e canais de comunicação e 2) a diversidade linguística e cultural (COPE; KALANTZIS, 2000, p. 5). Dessa forma, o conceito de 
multiletramentos indica os modos de comunicação que podem ser usados na prática de ensino, visto que o significado é produzido por meio de diversos recursos (como, por exemplo, recursos visuais, comportamentais, de áudio) que mudam a maneira como usamos a linguagem (CAZDEN et al., 1996, p. 64). Portanto, de acordo com Cazden et al. (1996, p. 64), a prática de ensino, a partir dessas teorias, prepara os alunos para a vida, desenvolvendo uma visão crítica do mundo.

Para que essa concepção de leitura possa ter se estabelecida, as discussões teóricas que determinaram outras concepções de leitura anteriores foram necessárias. Rojo (2004, p. 3-4) indica que nenhuma concepção invalida a outra: mas, mesmo com os avanços teóricos, "a leitura escolar parece ter parado no início da $2^{a}$ metade do século passado", ou seja, entendendo a leitura como decodificação.

A concepção de leitura como decodificação, estabelecida no início da primeira metade do século XX, remete a um "processo perceptual e associativo de decodificação de grafemas (escrita) em fonemas (fala) para se acessar o significado da linguagem do texto" (ROJO, 2004, p. 2). Ou seja, nesse entendimento, o processo de leitura é efetivo quando o leitor é capaz de oralizar o que está apresentado na linguagem escrita. Assim, esse processo está diretamente relacionado ao processo da alfabetização, quando entendido como o ato de associar os grafemas (letras, símbolos, sinais) com os fonemas (sons da fala) (ROJO, 2004, p. 2-3). Dessa forma, Rojo (2004, p. 3) aponta que "uma vez alfabetizado, uma vez construídas estas associações, o indivíduo poderia chegar da letra, à sílaba e à palavra, e delas, à frase, ao período, ao parágrafo e ao texto, acessando assim, linear e sucessivamente, seus significados". As capacidades de leitura envolvidas nesse processo, conforme apresenta Rojo (2004, p. 4), incluem:

compreender diferenças entre escrita e outras formas gráficas (outros sistemas de representação); dominar as convenções gráficas; conhecer o alfabeto; compreender a natureza alfabética do nosso sistema de escrita; dominar as relações entre grafemas e fonemas; saber decodificar palavras e textos escritos; saber ler reconhecendo globalmente as palavras; ampliar a sacada do olhar para porções maiores de texto que meras palavras, desenvolvendo assim fluência e rapidez de leitura. 
No contexto de ensino, os modelos ascendente e descendente de leitura, quando entendidos isoladamente, associados à concepção de leitura como decodificação, começaram a ser considerados insuficientes para um processo efetivo de leitura, visto que, conforme aponta Rojo (2004, p. 3), por meio do desenvolvimento de pesquisas ao longo dos anos 1900-1950, se percebeu que outras capacidades estão envolvidas no ato de ler, tais como "capacidades de ativação, reconhecimento e resgate de conhecimento, capacidades lógicas, capacidades de interação social etc." Assim, novamente, a concepção de leitura como construção de sentido demonstra-se a mais adequada para o ensino de leitura.

A partir dessa revisão das perspectivas de aprendizagem, concepções de linguagem, e concepções e modelos de leitura que guiaram e guiam o ensino de línguas no Brasil, o Quadro 1 foi elaborado para sintetizar e estabelecer relações entre as concepções apresentadas.

Quadro 1 - Perspectivas de aprendizagem e concepções de linguagem e de leitura

\begin{tabular}{|l|l|l|l|}
\hline $\begin{array}{l}\text { Perspectiva de } \\
\text { aprendizagem }\end{array}$ & Behaviorista & Cognitivista \\
\hline $\begin{array}{l}\text { Concepção de lin- } \\
\text { guagem }\end{array}$ & $\begin{array}{l}\text { Linguagem como } \\
\text { expressão do pensa- } \\
\text { mento }\end{array}$ & $\begin{array}{l}\text { Linguagem como } \\
\text { instrumento de co- } \\
\text { municação }\end{array}$ & $\begin{array}{l}\text { Linguagem como meio de intera- } \\
\text { ção, como gênero. }\end{array}$ \\
\hline $\begin{array}{l}\text { Concepção de lei- } \\
\text { tura }\end{array}$ & $\begin{array}{l}\text { Leitura como decodificação. } \\
\text { Modelos ascendente e descendente de leitura. }\end{array}$ & $\begin{array}{l}\text { Leitura como construção de sen- } \\
\text { tido, como letramento. } \\
\text { Modelo interativo de leitura. }\end{array}$ \\
\hline
\end{tabular}

Fonte: Elaborado pelas autoras

Cada uma dessas perspectivas e concepções se materializam nas práticas de ensino de diversas formas: nos livros didáticos, na prática de sala de aula dos professores, nos instrumentos de avaliação/testagem, entre outros. A próxima seção apresenta como o presente estudo buscou identificar as concepções de linguagem e de leitura em um instrumento de avaliação/testagem conhecido e aplicado nacionalmente: o Enem-LI. 


\section{Procedimentos de coleta e análise do corpus deste estudo}

Todas as edições do Enem estão disponíveis para download no site do Instituto $\mathrm{Na}$ cional de Estudos e Pesquisas Educacionais Anísio Teixeira (INEP) (BRASIL, 2015). O escopo do estudo inclui as edições do Enem aplicadas entre 2010 (quando as LE foram incluídas no exame) e 2017 (a edição mais recente no momento da coleta do corpus, realizada em março de 2018). Em relação a esse período, pelo menos duas versões diferentes do Enem foram aplicadas em cada ano, e as quatro áreas de conhecimento contempladas pelo exame (Ciências Humanas, Ciências da Natureza, Linguagens e Matemática) foram divididas em dois cadernos-teste, aplicados em dias diferentes. Assim, todos os cadernos-teste que incluíam o teste de Linguagens (em que estão inseridas as LE) e foram aplicados no período mencionado foram incluídos no corpus de análise no primeiro momento, totalizando então 17 testes. Como critério de delimitação do corpus, foram selecionadas as primeiras edições aplicadas em cada ano (de 2010 a 2017). Dessa forma, o total de exemplares analisados somou oito edições. Cada edição do Enem-LI apresenta cinco questões, o que totalizou então 40 questões analisadas.

Para a identificação das concepções de linguagem e de leitura que subjazem essas 40 questões, os procedimentos se voltaram para análise semântica do enunciado das questões ${ }^{2}$. Cada enunciado foi classificado de acordo com os tipos de informação que oferece aos examinandos acerca dos textos-base e os tipos de informação que demandam que os examinandos identifiquem nesses textos. Então, esses tipos de informação foram relacionados aos estratos da linguagem que mobilizam, a partir do entendimento do conceito da estratificação da linguagem da Linguística Sistêmico-Funcional (LSF) (MARTIN, 1992; HALLIDAY; MATTHIESSEN, 2014, p. 24), que foi adaptado pela Análise Crítica de Gêneros (ACG) (como, por exemplo em Hendges, 2005; Motta-Roth, 2008) para representar

\footnotetext{
${ }^{2}$ Este trabalho foi desenvolvido a partir de um estudo maior que analisou detalhadamente o ENEM-LI, e que resultou na dissertação de mestrado intitulada "Análise Crítica de Gênero do ENEM de Língua Inglesa" (RADÜNZ, 2020), defendida no Programa de Pós-graduação em Letras da UFSM e realizada com apoio da Coordenação de Aperfeiçoamento de Pessoal de Nível Superior - Brasil (CAPES) - Código de Financiamento 001, durante um ano. Esse estudo maior incluiu outros procedimentos de análise que possibilitaram o desenvolvimento do procedimento de análise descrito no presente artigo.
} 
a linguagem em seis níveis diferentes: Fonologia e Grafologia; Léxico-gramática; Semântica e Pragmática; Registro: contexto de situação; Gênero: contexto de cultura; e Discurso: ideologia. O Quadro 2 apresenta os conhecimentos linguísticos relacionados a cada estrato da linguagem, elaborado a partir de Motta-Roth (2008b), Gouveia (2009) e Halliday e Matthiessen (2014).

Quadro 2 - Os conhecimentos linguísticos relacionados aos estratos da linguagem

\begin{tabular}{|l|l|}
\hline $\begin{array}{c}\text { Estrato da lin- } \\
\text { guagem }\end{array}$ & \multicolumn{1}{c|}{ Conhecimentos linguísticos associados } \\
\hline Grafologia & \\
\hline Léxico-gramática & Os sistemas de escrita da língua. \\
\hline $\begin{array}{l}\text { As ações representadas no texto, bem como os participantes e as circunstâncias envolvi- } \\
\text { dos nessas ações (por meio de grupos verbais, nominais e adverbiais); e/ou os modos } \\
\text { oracionais (indicativo - declarativo ou interrogativo, e imperativo) utilizados no texto; } \\
\text { e/ou a estrutura textual (a posição das informações no texto). }\end{array}$ \\
\hline Pragmántica e & $\begin{array}{l}\text { As representações linguísticas, o assunto, o significado do texto; e/ou as trocas entre o } \\
\text { autor e o leitor estabelecidas pelo texto; e/ou a mensagem do texto. }\end{array}$ \\
\hline Registro & Os usos da linguagem e recursos linguísticos tipicamente relacionados a certos contextos. \\
\hline Gênero & $\begin{array}{l}\text { A relação entre o sistema linguístico, o contexto, e o objetivo social e comunicativo do } \\
\text { texto. }\end{array}$ \\
\hline Discurso & $\begin{array}{l}\text { As relações de poder e/ou hierarquia entre autor/leitor estabelecidas pelo texto; os dis- } \\
\text { cursos (político, religioso, etc.) permeados pelo texto; as ideologias apresentadas no texto. }\end{array}$ \\
\hline
\end{tabular}

Fonte: Radünz (2020); Marcuzzo; Radünz (no prelo).

Desse modo, foi considerado que os estratos do Discurso, Gênero e Registro mobilizam aspectos do contexto dos textos-base, o que pode conduzir a um entendimento de linguagem contextualizada como gênero, implicando uma concepção de leitura como construção de sentido - como letramento. Os outros estratos, da Semântica e Pragmática, Léxico-gramática e Fonologia e Grafologia, se mobilizados isoladamente, não compreendem os aspectos contextuais, o que pode conduzir a um entendimento de linguagem como expressão do pensamento ou instrumento de comunicação, implicando uma concepção de leitura como decodificação. Portanto, as 40 questões que compõem o corpus foram

${ }^{3}$ Visto que o presente estudo investiga um teste de leitura, a análise não precisou considerar aspectos da Fonologia. 
analisadas a fim de se identificar em que medida os enunciados e, consequentemente, as questões do Enem-LI, se alinham às concepções de linguagem e de leitura apresentadas no Quadro 1. A próxima seção apresenta os resultados alcançados por meio dessa análise.

\section{Concepções de linguagem e de leitura no Enem de Língua Inglesa}

O Enem-LI é composto de cinco questões em cada edição. Cada questão é composta de um texto-base escrito em LI, um enunciado e cinco alternativas de resposta, ambos escritos em Língua Portuguesa. Os enunciados das questões do Enem-LI são compostos, obrigatoriamente, de duas partes. Primeiro, os enunciados apresentam uma contextualização, em que são fornecidas, ao examinando, informações sobre o texto-base. Enquanto que, em algumas questões, essa contextualização apresenta uma simples referência ao texto-base (10\% das questões), na grande maioria, ela apresenta informações que dizem respeito à/a(ao) 1) generalizações sobre o gênero; 2) autoria; 3) assunto/tópico geral; 4) parte/conteúdo específico do texto; 5) generalizações sobre o contexto ou o público-alvo; e 6) local de publicação do texto-base.

Essa contextualização pode ser comparada a atividades de pré-leitura, mas, para que não indique uma "visão linear de leitura” (CARGNIN et al., 2018, p. 564), poderiam estar localizadas antes do texto-base. De acordo com Cargnin et al. (2018, p. 564), esses elementos pré-textuais, que, no caso do Enem-LI, são explorados pela contextualização dos enunciados, ajudam "a situar o leitor no contexto de consumo do texto, por exemplo, onde e quando foi publicado, quem é(são) o(s) autor(es), qual o público-alvo projetado”. Dessa forma, pode-se perceber que os tipos de informação apresentados na contextualização dos enunciados remetem principalmente aos Contextos de Cultura (Gênero) e de Situação (Registro) - com exceção das questões que apresentam, na contextualização, alguma informação acerca de uma parte ou de um conteúdo específico do texto-base, que remete à aspectos Semânticos e Pragmáticos (12,5\% das questões).

A segunda parte dos enunciados apresenta a demanda de informação em si, que, na maioria das questões, refere-se à(ao) 1) informações específicas acerca do conteúdo; 2) propósito; e 3) tópico do texto-base. Em menor ocorrência, as questões demandam que o 
examinando 4) estabeleça relações intertextuais; 5) identifique função de expressões; e 6) realize traduções. Assim, a maioria das questões demanda que o examinando ative conhecimentos relacionados a aspectos Semânticos e Pragmáticos para respondê-las: as que demandam informações específicas acerca do conteúdo dos textos-base e que demandam que o examinando estabeleça relações intertextuais; identifique função de expressões; e realize traduções. Por outro lado, algumas questões demandam conhecimentos relacionados a aspectos do Contexto de Situação (Registro): as questões que demandam o propósito ou o tópico do texto-base 4 .

Nesse cenário, foi possível identificar duas concepções de linguagem e de leitura exploradas em diferentes questões do Enem-LI. Em 57,5\% das questões, foi possível identificar um direcionamento para a concepção de linguagem como meio de interação, como gênero e de leitura como construção de sentido, como letramento. Por outro lado, em $42,5 \%$ das questões, as concepções identificadas foram a concepção de linguagem como instrumento de comunicação e de leitura como decodificação.

Em questões que realizam a demanda de informação, após apresentarem, na contextualização, informações sobre o gênero, o contexto, o público-alvo, a autoria, o assunto/tópico geral ou o local de publicação do texto-base, conforme exemplificado pelas Figuras $1^{5}$ e $2^{6}$, é possível verificar uma inclinação para a concepção de linguagem como meio de interação, como gênero e de leitura como construção de sentido, como letramento. Essas concepções puderam ser verificadas, mesmo que timidamente, na medida em que essas questões apresentam informações contextuais antes de demandar informações textuais, ou até mesmo contextuais. Ou seja, nessas questões, as informações contextuais são consideradas tão importantes quanto às informações textuais. Porém, para que essas concepções se efetivem, conforme mencionado anteriormente, a contextualização do enunciado deveria estar posicionada antes do texto-base, e poderia abordar também aspectos

\footnotetext{
${ }^{4}$ Resultados da pesquisa apresentada em Radünz (2020) e Marcuzzo e Radünz (no prelo).

${ }^{5}$ Questão-modelo da edição de 2017 do ENEM, caderno azul.

${ }^{6}$ Questão-modelo da edição de 2015 do ENEM, caderno amarelo.
} 
relacionados ao Discurso do texto-base, como, por exemplo, "relacionados à inclusão/exclusão de participantes, e representações e vozes atribuídas" a eles (KUMMER, 2015, p. 108). Dessa forma, pode-se considerar que, no Enem-LI, pode ser identificada uma visão de linguagem como gênero, mas ainda não uma visão crítica, que remete ao entendimento das ideologias, por exemplo, presentes no texto.

Por outro lado, confirmando as análises feitas por Rauber (2012) e Avelar (2015), em questões que realizam a demanda de informação após apresentarem, na contextualização, informações sobre alguma parte ou o conteúdo específico do texto-base, sem nenhuma menção ao contexto, conforme exemplificado pelas Figuras $3^{7}$ e $4^{8}$, é possível verificar a concepção de linguagem como instrumento de comunicação e de leitura como decodificação. Essas concepções puderam ser verificadas na medida em que nessas questões o examinando não estabelece nenhuma relação entre texto e contexto: o texto-base é mencionado pelo enunciado, e, então, o examinando precisa simplesmente identificar alguma informação, sem refletir sobre quem escreveu esse texto, com quais objetivos, para qual público-alvo, etc. Portanto, em algumas questões, é suficiente que o examinando realize uma simples decodificação das palavras presentes nos textos-base. 
Figura 1 - concepção de linguagem como gênero/leitura como letramento no ENEM-LI

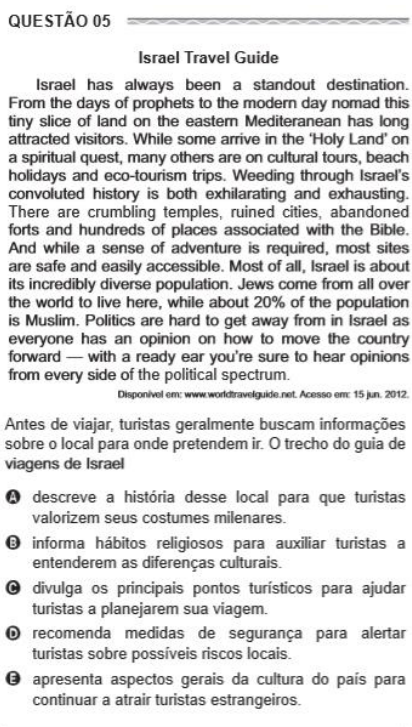

Fonte: Brasil (2015)
Figura 2 - concepção de linguagem como gênero/leitura como letramento no ENEM-LI

QUESTÃO 94

Why am I compelled to write? Because the writing saves me from this complacency I fear. Because I have no choice. Because I must keep the spirit of my revolt and myself alive. Because the world I create in the writing compensates for what the real world does not give me. By writing I put order in the world, give it a handle so I can grasp it.

ANZALDÚA, G. E. Speaking in tongues: a letter to third world women writers. In: HERNANDEZ, J. B. (Ed.). Women writing resistance: essays on Latin America and the Caribbean. Boston: South End, 2003

Gloria Evangelina Anzaldúa, falecida em 2004, foi uma escritora americana de origem mexicana que escreveu sobre questões culturais e raciais. Na citação, o intuito da autora é evidenciar as

A razöes pelas quais ela escreve.

B compensaçôes advindas da escrita.

C possibilidades de mudar o mundo real.

(D) maneiras de ela lidar com seus medos.

(E) escolhas que ela faz para ordenar o mundo.

Fonte: Brasil (2015)

Figura 4 - concepção de linguagem como instrumento de comunicação/leitura como decodificação no ENEM-LI

\section{QUESTÃO 92}

\section{If You Can't Master English, Try Globish}

PARIS - It happens all the time: during an airport delay the man to the left, a Korean perhaps, starts talking to the man opposite, who might be Colombian, and soon they are chatting away in what seems to be English. But the native English speaker sitting between them cannot understand a word.

They don't know it, but the Korean and the Colombian are speaking Globish, the latest addition to the 6,800 languages that are said to be spoken across the world. Not that its inventor, Jean-Paul Nerrière, considers it a proper language.

"It is not a language, it is a tool," he says. "A language is the vehicle of a culture. Globish doesn't want to be that at all. It is a means of communication."

Nerrière doesn't see Globish in the same light as utopian efforts such as Kosmos, Volapuk, Novial or staunch Esperanto. Nor should it be confused with barbaric Algol (for Algorithmic language). It is a sort of English lite: a means of simplifying the language and giving it rules so it can be understood by all.

BLUME, M. Disponivel em: www.nytimes.com. Acesso em: 28 out. 2013 (fragmento).

Considerando as ideias apresentadas no texto, o Globish (Global English) é uma variedade da língua inglesa que

A tem status de língua por refletir uma cultura global.

B facilita o entendimento entre o falante nativo e o não nativo.

C tem as mesmas características de projetos utópicos como o esperanto.

D altera a estrutura do idioma para possibilitar a comunicação internacional.

G apresenta padrões de fala idênticos aos da variedade usada pelos falantes nativos.

Fonte: Brasil (2015) 
Figura 3 - concepção de linguagem como instrumento de comunicação/leitura como decodificação no ENEM-LI

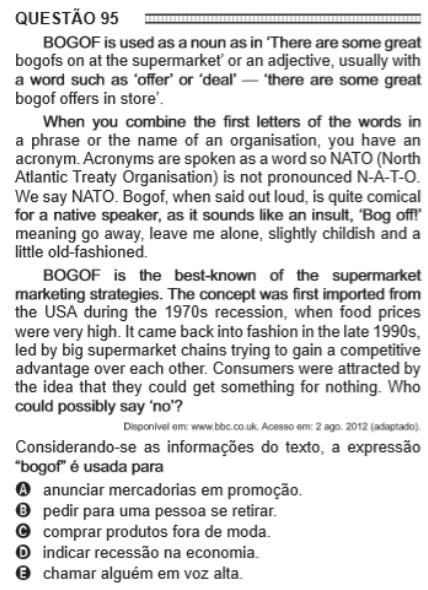

Fonte: Brasil (2015)

Na Figura 1, a questão-modelo apresenta, na contextualização do enunciado, generalizações sobre o público-alvo do texto-base: turistas, ou seja, uma informação contextual referente ao Gênero. Após essa contextualização, o enunciado demanda o objetivo do texto-base, também uma informação contextual, referente ao Registro. Na Figura 2, da mesma forma, o enunciado apresenta, na contextualização, informações sobre a autora do texto-base, incluindo suas origens e seu tópico principal de escrita, ou seja, uma informação contextual referente ao Registro. Após a contextualização, o enunciado demanda o objetivo da autora do texto-base, novamente uma informação contextual referente ao Registro.

Na Figura 3, o enunciado apresenta, na contextualização, uma simples referência ao texto-base, sem incluir nenhuma informação contextual, e, em seguida, demanda a função/o significado de uma expressão utilizada no texto. Assim, o examinando precisará ler o texto para identificar a expressão e seu significado, sem refletir sobre o contexto em que essa expressão é utilizada, com quais objetivos, por quais participantes, etc. Assim também, na Figura 4, a contextualização simplesmente se refere às "ideias apresentadas no texto", sem indicar o gênero do texto-base ou informações sobre autoria. E, então, o enunciado 
demanda uma informação específica acerca do conteúdo do texto-base: uma das características da variedade da língua inglesa apresentada pelo texto.

Portanto, a partir da análise das questões do Enem-LI, foi possível identificar que o teste, em algumas questões, está alinhado a uma concepção de linguagem como meio de interação, como gênero, e de leitura como construção de sentido, como letramento e, em outras, está alinhado a uma concepção de linguagem como instrumento de comunicação e de leitura como decodificação. O direcionamento do Enem-LI para a concepção de linguagem como gênero pode ser considerado um aspecto positivo do teste, visto que essa concepção implica leitores que são capazes de explicar e localizar "os elementos linguísticos no tempo e no espaço" e desnaturalizar "os valores que estão postos" (MOTTA-ROTH, 2008, p. 370). Assim, o Enem, que, em certa medida, exerce influências nos contextos escolares, pode representar um dos caminhos para ajudar a implementar o ensino de língua inglesa mais voltado para os contextos de uso da língua.

\section{Considerações finais}

O presente trabalho apresenta uma nova visão para as concepções de linguagem e de leitura que subjazem o Enem-LI, na medida em que identificou aspectos que revelam um direcionamento para o entendimento da linguagem como gênero. Apesar desse direcionamento ter sido identificado em um pouco mais da metade dos itens analisados, esse resultado sugere que a concepção de leitura como decodificação, apontada até então pelos estudos prévios sobre o tema, não é a única presente no teste.

A palavra “direcionamento" é utilizada por nós para indicar que não é possível afirmar que as concepções de linguagem como gênero e de leitura como letramento estão completamente estabelecidas no teste, principalmente no que diz respeito aos aspectos ideológicos, que, uma vez presentes, indicariam uma visão crítica de linguagem. Para que essas concepções de linguagem e de leitura, defendidas também pelos documentos oficiais que orientam a elaboração do exame, se estabeleçam no Enem-LI, fazemos algumas sugestões:

1) modificação da estrutura retórica dos itens, apresentando primeiramente o enunciado e as alternativas de resposta, e, por último, o texto-base. Essa ordem auxiliaria o 
examinando no processo de leitura, visto que os enunciados apresentam, na contextualização, informações que situam o texto em seu contexto e servem como uma pré-leitura;

2) apresentação dos textos-base conforme seus layouts e extensões originais, visto que muitos itens apresentam apenas fragmentos dos textos, e modificam o layout original. O texto-base em seu layout original aproximaria o examinando das práticas sociais em que o texto realmente circula; e

3) inclusão de mais questões por texto-base - como também apontado por Blanco (2013, p. 97), para que aspectos mais abstratos dos textos possam ser explorados. Assim, após uma contextualização sobre o texto-base, os enunciados poderiam apresentar mais de uma questão, em que cada uma delas abordaria um aspecto diferente da linguagem, começando por aspectos mais concretos, referentes à Léxico-gramática e Semântica e Pragmática, para então abordar aspectos mais abstratos, referentes ao Registro, Gênero e Discurso. Esse caminho de explorar, em primeiro lugar, aspectos mais concretos da linguagem, para então partir para aspectos mais abstratos., refere-se à teoria dos andaimes, em que um instrutor mais experiente "controla" os elementos de uma tarefa que está além da capacidade do aprendiz, e, portanto, auxilia o aprendiz a desempenhar essa tarefa (WOOD et al., 1976, p. 90), traçando paralelos com a ZDP de Vygotsky (NEWMANN; HOLZMAN, 1993, p. 87). No caso do Enem-LI, cada questão prévia serviria como um andaime para a próxima, para que o examinando pudesse construir significados desde o conteúdo até aspectos ideológicos dos textos-base.

\section{LANGUAGE AND READING CONCEPTIONS IN ENGLISH LANGUAGE ENEM}

ABSTRACT: In Brazil, the High School National Exam (Enem) influences teaching contexts since it is used as a criterion to apply to important public and private universities and as a criterion to participate in social projects that enable this access. Enem's influences in teaching contexts include theoretical conceptions that underly it, since the questions that compose the exam are based on theories that, consequently, guide school practices. The objective of this article is to analyze the language and reading conceptions that underly the English Language Enem (EL-Enem). Thus, we considered, mainly, the conceptions of language as interaction and as a communication instrument; and the conceptions of reading as meaning production and as decoding. Forty EL questions from eight editions of the exam were analyzed, with emphasis on the semantic analysis of the questions' instructions. The results point that both language and reading conceptions underly different questions of the exam, 
which may indicate a direction for latest views of language as genre and reading as literacy, privileged by official documents that guide language teaching in the country.

KEYWORDS: English Language; Enem; Language conceptions; Reading conceptions.

\section{REFERÊNCIAS}

AVELAR, F. J. S. O inglês no Enem e na escola: práticas de dois professores do ensino médio. 2015, 275 p. Tese de doutorado. Universidade Estadual de Campinas, Campinas, SP, 2015.

BAKHTIN, M. Marxismo e Filosofia da Linguagem. 9. ed. São Paulo: Hucitec, 1999.

BLANCO, J. A avaliação de língua inglesa no Enem: efeitos de seu impacto social no contexto escolar. 2013, 132 p. Dissertação de mestrado. Universidade Federal de São Carlos, São Carlos, SP, 2013.

BRASIL. Instituto Nacional de Estudos e Pesquisas Educacionais Anísio Teixeira. Portal INEP. Brasília, 2015. Disponível em: http://portal.inep.gov.br/web/guest/enem. Acesso em: 20 mar. 2018.

BRASIL. Ministério da Educação. Secretaria de Educação Básica. Orientações curriculares para o Ensino Médio. Brasília, 2006.

BRASIL. Ministério da Educação. Secretaria de Educação Fundamental. Parâmetros curriculares nacionais: terceiro e quarto ciclos do ensino fundamental: língua estrangeira. Brasília, 1998.

CARGNIN, E. S.; ROSSI, A. M.; TICKS, L. K. Concepções de ensino e aprendizagem subjacentes às atividades do livro didático português: projeto teláris. Domínios da Lingu@gem,n. 12, v. 1, p.551-580, 2018.

CAZDEN, K. et al. A pedagogy of multiliteracies: designing social futures. Harvey Educational Review, v. 66, n. 1, p. 60-92, 1996.

CERVETTI, G. N.; PARDALES, M. J.; DAMICO, J. S. A tale of differences: comparing the traditions, perspectives, and educational goals of critical reading and critical literacy.

Reading Online, v. 4, n. 9, 2001. Disponível em: https://www.researchgate.net/publication/334372467_A_Tale_of_Differences_Comparing_the_Traditions_Perspectives_and_Educational_Goals_of_Critical_Reading_and_Critical_Literacy.

CHOMSKY, N. A biolinguística e a capacidade humana. In: Linguagem e mente. São Paulo: Editora da UNESP, p. 311-332, 2009.

COPE, B.; KALANTZIS, M. The Powers of Literacy: A Genre Approach to Teaching Writing, edited by Pitsburgh: University of Pitsburgh Press, 1993. 
COPE, B.; KALANTZIS, M. Multiliteracies: literacy learning and the design of social features. New York/London: Routledge, 2000.

FRIEDRICH, J. A formação dos conceitos na criança. In: Lev Vigotski - Mediação, aprendizagem e desenvolvimento: Uma leitura filosófica e epistemológica. Campinas, SP: Mercado de Letras, p. 77-98, 2012.

FUZA, A. F.; MENEGASSI, R. J. Concepções de linguagem e de leitura na prova Brasil. Linguas e Letras, v. 10, n. 18, p. 13-32, 2009.

GOMES, R. As concepções de linguagem e o ensino de língua materna: um percurso. Letras Escreve, v. 3, n. 1, p. 41-47, 2013.

GOUVEIA, C. A. M. Texto e gramática: uma introdução à Linguística Sistêmico-Funcional. Matraga, v. 16, n. 24, p. 13-47, 2009.

HALLIDAY, M. A. K.; MATTHIESSEN, C. M. I. M. Halliday's Introduction to Functional Grammar. New York/London: Routledge, 2014.

HENDGES, G. R. A genre and register analysis of electronic research articles from a systemic functional perspective: new medium, new meanings. PHD project. Florianópolis: PPGI/UFSC, 2005.

KATO, M. A contribuição chomskiana para a compreensão da aprendizagem de L2. Trabalhos em Linguistica Aplicada, v. 44, n. 2, p. 185-199, 2005.

KUMMER, D. A. Letramento Multimodal Crítico: sob a perspectiva de livros didáticos e de professores de inglês e de biologia. 2015, 149 p. Dissertação de mestrado. Universidade Federal de Santa Maria, Santa Maria, RS, 2015.

MARCUZZO, P.; RADÜNZ, A. P. Analysing a test as genre: Critical Genre Analysis of the English Language Enem. D.E.L.T.A., São Paulo, no prelo.

MARTIN, J. R. English text: system and structure. Philadelphia/Amsterdam: John Benjamins, 1992.

MOTTA-ROTH, D. Questões de metodologia em análise de gêneros. In: KARWOSKI, A. M.; GAYDECZKA, B.; BRITO, K. S. (Org.). Gêneros textuais: reflexões e ensino. 2ed. Rio de Janeiro: Editora Lucerna, 2006. p. 145-163.

MOTTA-ROTH, D. Análise Crítica de Gêneros: contribuições para o ensino de linguagem. D. E. L. T. A., São Paulo, v. 24, n. 2, p. 341-383, 2008.

MUNARI, A. Ensaio. In: SAHEB, D. Jean Piaget. Recife: Fundação Joaquim Nabuco, Editora Massangana, p. 11-26, 2010.

NEWMAN, F. \& HOLZMAN, L. Praxis: A zona de desenvolvimento proximal. In: 1993.

. Lev Vygotsky: Cientista revolucionário. São Paulo: Editora Loyola, p. 71-110, 
NUTTALL, C. Teaching reading skills in a foreign language. Oxford: Heinemann, 1996.

RADÜNZ, A. P. Análise Crítica de Gênero do ENEM de Lingua Inglesa. 2020, 98 p.

Dissertação de mestrado. Universidade Federal de Santa Maria, Santa Maria, RS, 2020.

RAUBER, B. B. Avaliação em língua estrangeira (inglês) no acesso ao ensino superior: O Enem em discussão. 2012, 110 p. Dissertação de mestrado. Universidade Federal de São Carlos, São Carlos, SP, 2012.

ROJO, R. Letramento e capacidades de leitura para a cidadania. São Paulo, See: CenP, 2004. Retirado de: http:/ / files.saladeleitura-dera.webnode.com/200000194-

e3ca4e4c46/ROJO\%20CAPACIDADES\%20DE\%20LEITURA.pdf. Acesso em: 12 junho 2020 .

VYGOTSKY, L. S. As raízes genéticas do pensamento e da linguagem. In: - $A$ construção do pensamento e da linguagem. São Paulo: Editora Martins Fontes, p. 111-150, 2001.

WOOD, D.; BRUNER, J. S.; ROSS, G. The role of tutoring in problem solving. Journal of child psychology and psychiatry, v. 17, n. 2, p. 89-100, 1976.

Recebido em: 20/07/2020.

Aprovado em: 15/10/2020. 